\title{
Breaking Green Ceilings: podcasting for environmental and social change
}

\author{
Sapna Mulki ${ }^{1}$ (D) Alison A. Ormsby² ${ }^{2}$
}

Accepted: 21 September 2021 / Published online: 2 November 2021

(c) AESS 2021

\begin{abstract}
Podcasting is considered to be a communication medium with minimal barriers to entry, making it an attractive method for people, especially from historically underrepresented communities, to tell their own stories. Using the "Breaking Green Ceilings" podcast as a case study, we explore how podcasting serves as an ideal approach to effectively amplify the voices of environmentalists from historically underrepresented communities, specifically Disabled, Queer, Trans, Black, Indigenous, and People of Color. By sharing these stories, the podcast aims to challenge misconceptions and highlight the contributions that environmentalists from historically underrepresented communities make toward environmental sustainability at all levels—grassroots, academia, nonprofit, and government. The "Breaking Green Ceilings" podcast also helps address the lack of diversity in mainstream environmental media and organizations. We use an interdisciplinary, intersectional lens in this article to demonstrate how environmental issues are interconnected with race, religion, socio-economic status, and politics as relates to historically underrepresented communities. We explore four main themes that have emerged on the podcast: environmental justice, structural racism and conservation, traditional ecological knowledge, and access to nature and the outdoors. Finally, strategies are provided to show how the podcast goes beyond the airwaves to build an inclusive community, raising awareness on the issues discussed and moving people to action to undo and unlearn some of the harmful practices and attitudes that have divided the environmental movement for decades.
\end{abstract}

Keywords Environmental communication · Environmental justice $\cdot$ Environmental media $\cdot$ Intersectionality $\cdot$ Just sustainability · Traditional ecological knowledge

\section{Introduction and background}

This article discusses the value that podcasting brings to creating a platform to amplify the voices and contributions of environmentalists from historically underrepresented communities. The environmental podcast Breaking Green Ceilings is used as a case study to demonstrate a way to explain and propose solutions to the persistent challenges that environmentalists from historically underrepresented communities often face in mainstream environmental organizations

Sapna Mulki

sapna@watersavvysolutions.com

Alison A. Ormsby

aormsby@unca.edu

1 Columbus, $\mathrm{OH}, \mathrm{USA}$

2 Environmental Studies, University of North Carolina Asheville, One University Heights, Asheville, NC 28804, USA and media. Another goal of the podcast is to share stories that often are not covered in education systems and by mainstream media.

This article provides evidence for the lack of representation in environmental organizations, and how podcasting can help boost this representation and awareness by providing a space where individuals can freely express themselves and their experiences without judgment. The podcasting format also allows for participants to share accounts of their contributions to promote environmental justice without censorship.

A groundbreaking comprehensive study was conducted on the state of workforce diversity in the environmental movement by surveying 191 environmental non-profits, 74 government environmental agencies, and 28 leading environmental grantmaking foundations to investigate their gender and racial diversity composition (Taylor 2014). The resulting report, "The State of Diversity in Environmental Organizations," revealed that "The percentage of ethnic 
minorities on the boards or general staff of environmental organizations does not exceed 16 percent" (Taylor 2014, p. 4). The report also concluded that, "once hired in environmental organizations, ethnic minorities are concentrated in the lower ranks. As a result, people of color occupy less than 12 percent of the leadership positions in the environmental organizations" (Taylor 2014, p. 4). The constant failure of the green movement to improve these low percentages is known as the "green ceiling," to indicate that there are barriers to inclusion and active hiring of historically underrepresented individuals within environmental organizations, particularly in leadership roles.

Hempel (2011, p. 47) defined a test to ensure true sustainability, which requires "a synergy of social justice, ecological health, and economic vitality." These three categories match with the traditional three pillars of sustainability-social, economic, and environmental. In the 1980s, the Brundtland Report defined development as sustainable if it "meets the needs of the present without compromising the ability of future generations to meet their own needs" (1987, p. 16). However, this definition of sustainability has been challenged more recently. There has been a lack of representation of people from historically underrepresented communities within the environmental movement in the United States (Taylor 2014) and a separation of environmental justice from sustainability or conservation efforts. Thus, the environmental movement has not yet adequately pursued all of the elements of true sustainability, or what Agyeman (2005) calls "just sustainability." As Agyeman explains (2005, p. 5), "the concept of just sustainability highlights the pivotal role that justice and equity could and should play within sustainability discourses." Pellow (2018) calls for critical environmental justice efforts that include four pillars: intersectionality; multi-scalar; focus on social inequity; and recognizing that we are all interdependent.

Breaking Green Ceilings is a weekly podcast that intentionally prioritizes the experiences of environmentalists from historically underrepresented communities, including Disabled, Queer, Trans, Black, Indigenous, and People of Color. Discussions in the podcast take an intersectional approach, looking at how social identities-such as race, ethnicity, social class, religion, sexual orientation, and gender identity-overlap with one another and with oppressive systems of power that shape the experiences of the guests in their workplaces, activism, and broader community (Crenshaw 1989, 2015). An interdisciplinary, intersectional approach captures the reality of the interconnectedness of environmental, social, and economic issues. The topics, issues, and discussions in the podcast cover both the natural and social sciences and are primarily focused on the United States. However, some guests and conversations also include global perspectives. Two main topics are explored in the podcast: (1) Environmental challenges that are exacerbated for historically underrepresented communities due to oppressive systems such as structural racism and white supremacy, and (2) movements-such as environmental justice and disability justice- that have formed in response to, and in an effort to, dismantle these oppressive systems. Examples of systems of structural racism in the United States include mass incarceration, hiring practices, unequal access to education and health care, and redlining (Alexander 2010).

Despite the fact that podcasting has been around for over 15 years and there are already many podcasts, the space is not overcrowded and is still growing steadily. Podcasting increased in popularity in the mid-2000s with the advent of broadband Internet access and portable digital audio playback devices such as the iPod (Hammersley 2004). Today, there are over $1,700,000$ podcasts (Listen Notes 2020).

Podcasting is an accessible platform particularly for diverse audiences because it is still a fairly young and decentralized medium, having started only in 2005 (Bottomley 2015). Anyone can create a podcast as long as they have a topic idea and can afford the basic cost of a microphone, headphones, a laptop, and a hosting platform. The cost can increase based on how much one wants to invest in equipment, editing, content development, and marketing. The start-up cost of podcasts ranges anywhere from $\$ 100$ to $\$ 3,000$ (Ruoff 2018). Additionally, recurring costs are manageable and predictable. The main resource that is required is time for production and content development.

In addition to the relatively low start-up costs, podcasting is not regulated, meaning that platforms where podcasts are uploaded, such as Apple Podcasts, Spotify, and Google Music, do not control the type of content that they allow to be shared. Thus, one can see why podcasting is an attractive option for a person or a group of people who have historically been underrepresented and not featured in mainstream culture or media such as Disabled, Queer, Trans, Black, Indigenous, and People of Color (DQTBIPOC) (Piepzna-Samarasinha 2018). Podcasts also allow listeners to choose the time of listening and content (Markman and Sawyer 2014).

Podcasting is a format that easily allows "expression of compound and networked forms of knowledge" (Barrios-O'Neill 2018, p. 147). Thus, in the extended and conversational interview format of a podcast, complex issues can be given the time and depth needed. Supporting social media and additional information can also help present multi-faceted, interdisciplinary topics. Podcasts can use "conversation as a mode of inquiry" (BarriosO'Neill 2018, p. 151). The Breaking Green Ceilings (BGC) podcast's themes demonstrate how environmental issues are interconnected with racial, cultural, social, economic, 
and political issues and that historically underrepresented communities are disproportionately impacted by climate change, environmental degradation, and loss of biodiversity. This article presents the steps taken to launch the BGC podcast and topics covered in the first year of the podcast, as well as future directions and goals for the show.

\section{Methods: creating the Breaking Green Ceilings podcast}

The first author had the initial idea to create the BGC podcast in February 2019, one year before the podcast actually launched. During the year, she undertook a number of activities to determine the viability of the podcast idea, including conducting market research to determine the following:

1. Current number of active environmental podcasts and the themes covered under each, and how much they prioritized experiences of DQTBIPOC.

2. Availability and possible quantity of environmentalists to interview over a span of at least two years.

3. Equipment and production costs.

4. Time commitment required to produce episodes and implement a marketing strategy.

5. Demand or level of interest based on feedback from potential listeners and guests.

Using a convenience sampling approach (Neuman 2006), the podcast creator interviewed five key informants in the field of podcasts to determine viability of the BGC idea. Interviews were conducted with other women of color in the podcasting world, such as the Founder of Women of Color Podcasters, Danielle Desir, the host of Desi Women Diaspora, Mala Kumar, and Kristy Drutman of Brown Girl Green.

After completing the market research, a decision was made to go forward with the podcast. Necessary equipment was purchased, and interviews with the first guests were scheduled. The podcast was first released in February 2020. Since its launch, 40 episodes were produced in the first season, which consisted of nine months. Each episode is approximately one hour long. The format of the interviews is one-on-one conversations between the host, Sapna Mulki, and the guest.

The BGC podcast represents individuals who are committed to environmental sustainability and social justice issues, because the two are inextricably linked. The podcast seeks to break through the longstanding barriers that people of color have faced in mainstream environmental organizations, as explained in the Green 2.0 report (Taylor 2014). While people of color currently do not make up a significant percentage of the workforce in environmental organizations, they are making substantial contributions to sustainability. Breaking Green Ceilings seeks out and amplifies these voices, thus celebrating diversity of thought, which is critical to creating holistic solutions for our environmental challenges.

Lack of representation also poses a challenge in terms of podcasts that are available to the mainstream environmental community. Based on our research, we identified approximately 142 environmental podcasts. To assemble this list, the authors reviewed the topics covered by the podcast to be sure that environmental issues are covered, with any nature-focused topics from any discipline. We analyzed lists of podcasts from Apple iTunes, Spotify, and player. $\mathrm{fm}$, as well as searches using Google and Instagram. We acknowledge that this list is not comprehensive. Out of 142 environmentally themed podcasts that were analyzed, based on the podcast host profiles and show notes, $46 \%$ of them have White male hosts, $34 \%$ have White female hosts, and interestingly $14 \%$ have female BIPOC hosts and $6 \%$ male BIPOC hosts (Fig. 1). Some podcasts have co-hosts; thus, we counted all hosts in our analysis. While this analysis is subjective, BIPOC hosts tend to self-identify within the podcast descriptions. These host patterns are presented to show a trend, but not to represent a comprehensive synthesis. Markman and Sawyer (2014, p. 20) reported that "Results from a web-based survey found that podcasting continues to be dominated by educated, professional males over 30 , most of whom are not podcasting full-time."

Before embarking on creating the BGC podcast, the host identified the target audience and created an audience profile, based on answering the following questions:

1. What are their general interests?

2. Do they listen to podcasts?

3. How do they consume information?

4. What are the benefits for the podcast listener?

5. What challenges does the podcast address?

6. What curiosities do listeners have, and does the podcast fulfill this?

7. What do you want listeners to do after hearing the podcast; what is the call to action?

For BGC, initial research-conducted by the podcast host-focused on assessing representation of people of color in the environmental movement. The preparatory research also explored the level of representation of people of color in mainstream media, particularly in podcasting. Formal research reports such as Green 2.0 also informed the question, to what extent are environmentalists of color heard in mainstream society?

Conversations with people of color in the environmental field, using convenience sampling, further confirmed the 
Fig. 1 Environmental podcast host representation

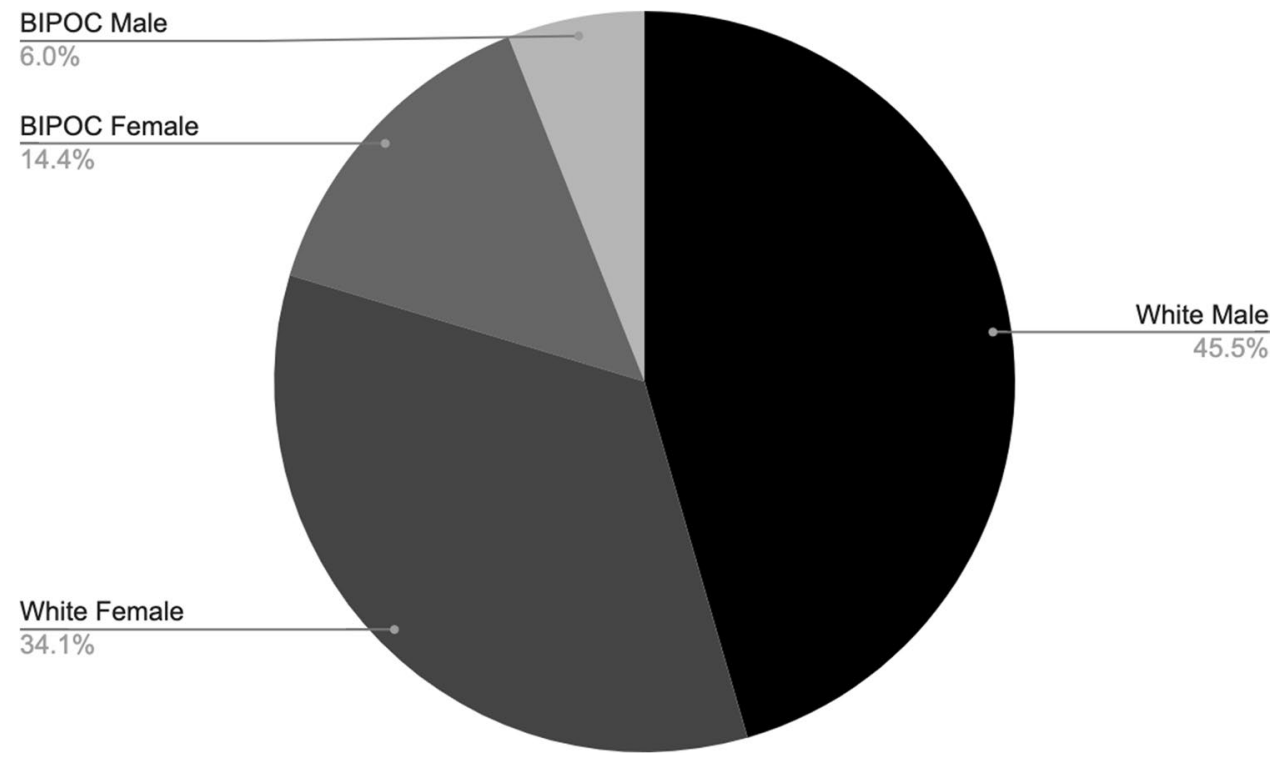

findings from the Green 2.0 report. Information was gathered on people's experiences working in large environmental organizations such as the Sierra Club and National Wildlife Federation. The host also communicated with women in the water and wastewater industry who shared sentiments on there not being enough female representation in the field. In total, the first author conducted 10 informal interviews to gain perspectives of what it is like being minoritized in environmental work and how a podcast might help amplify their voices and contributions to environmental sustainability.

Based on research and conversations with stakeholders and the target audience, over time the host established the following goals for the BGC podcast:

- Create a community for DQTBIPOC environmentalists to learn from and connect with each other.

- Provide a platform that amplifies the voices of DQTBIPOC environmentalists to share stories on their own terms.

- Amplify the voices of historically underrepresented DQTBIPOC communities, who are disproportionately impacted by climate change, and environmental degradation and pollution, and include these communities in the solutions developed locally and globally.

It was important to be able to demonstrate the interconnectedness of environmentalism with social, economic, cultural, and political issues, as Hempel (2011) identified as passing the "Sustainability Test." This is also a prerequisite to a broader, expanded way to be ecoliterate (Hempel 2014) and to manifest "just sustainability" (Agyeman 2005). Thus, the structure of the interviews for $\mathrm{BGC}$ is such that it explores this dynamic at the individual level by sharing personal stories of interacting with the natural environment and also involvement on a particular environmental issue.

It was equally important to feature a cross-section of expertise from youth to elders, from undergraduate students to professors, and from activists to consultants to project managers. The podcast features individuals who do not necessarily have a formal education in environmental topics but are making significant contributions towards educating and advocating for a sustainable environment.

Additionally, various themes have been explored in BGC episodes, such as the power of social media in communicating environmental issues, environmental racism, the role that structural racism plays in conservation, and also the impact that White allies are making in advancing more representation of historically underrepresented communities and equity within organizations.

Everything related to the podcast has been funded by the podcast host, from the market research to purchasing equipment (microphones and headsets), to producing the podcast. The weekly, non-serial podcast launched in February 2020. Within two months of the launch, the scope of the target audience was expanded, based on the information and trends gathered through social media platforms, primarily Instagram. It was observed that there are influencers, such as adaptive athlete Vasu Sojitra (vasusojitra.com), who represents disabled and queer communities and uses their platforms to educate and raise awareness about their experiences interacting with the natural environment and how they are impacted by environmental degradation and climate change. Therefore, these guests were added to the list of possible interviewees, which is constantly expanding. 
Over time, the broad category of people of color has been broken down to recognize the unique circumstances of Black and Indigenous people. These groups have a longer and more brutal history in the United States, and topics are explored such as how the making of the concept American "wilderness" has impacted them (Taylor 2016). White allies have been featured on BGC as a way to demonstrate their importance in creating a stronger movement that helps elevate the causes of DQTBIPOC environmentalists.

To summarize, it is important to research the intended target audience before starting a podcast through market research including by surveying potential listeners and guests. Hosts should continue to gather data even after launch, to determine if the defined target audience needs to expand or be clarified.

\section{Inclusive practices followed on BGC}

It is important that the podcast guest feels fully heard and represented throughout the process-recruiting, interviewing, and episode launch. It is especially important that guest speakers of color are treated with the full dignity and respect that they deserve, and are recognized as the experts that they are.

Additionally, through an intentional process of recruiting, it was possible to prioritize representation of guests who identify in at least one of the following categories: Disabled, LGBTQ+, Black, Indigenous, and People of Color. Creating a space for guests from historically underrepresented communities to talk about their love for the environment helps challenge misconceptions that may exist. Individuals from historically underrepresented communities often face negative stereotypes and biases. Therefore, interview questions are designed to humanize the guest and their individual experiences in an attempt to build a bridge of understanding between the guest and listener.

The theme of intersectionality once again comes into play through the questions that highlight guest speakers' personalities, histories, cultures, expertise, and how that influences their approach to developing environmental solutions. By asking questions that focus on the personal and the professional, listeners gain insight into the inequalities and injustices that guests have faced. Listeners also get to hear about the aspirations and successes of the guest speakers and how they have overcome challenges. The hope from implementing inclusive practices is also that guests can serve as examples for environmental organizations to prioritize and implement diversity and inclusion.

Inclusive language is a major element of creating a positive experience for the guest. For example, guests provide their pronouns. Specific terminology is clarified in the pre-interview such prescribed burn, which is more westernized versus cultural burn, which is a term preferred by Indigenous people. A general approach to developing questions for BGC is that nothing is assumed about the guest speaker. Questions are based on paying attention to the language of the guest and the information that the speaker shares about themselves.

\section{Guest recruiting and $B G C$ ethics}

There are several factors that are taken into consideration when selecting a guest for the BGC podcast, including the following:

1. DQTBIPOC - the guest is representative of the community. The guest is vocal about the disparities that their community experiences.

2. Commitment to intersectionality - the guests are willing to share how their racial and social identity affects how they are perceived in society, and how that impacts their environmental work.

3. Adversity and success - the guests are able to share the challenges that they have experienced and the steps that they are taking to address these adversities.

The relationship between host and guest is based on transparency and inclusion. Guests who are invited and agree to be on the BGC podcast are provided with detailed information on the pre- and post-production process. The interview questions are shared with guests prior to the recording session in order to allow them to prepare and feel comfortable with the process. An unrecorded pre-interview is also conducted where the host and guest get to know each other and establish rapport to the extent possible. The purpose of this step is also to build trust between each other and to identify specific aspects of their work that directly relates to the goals of the podcast.

It is important that the guests feel a sense of control and agency over the process because they are bringing their authentic and vulnerable selves to the podcast and the public, in a world where they often face discrimination. It is critical to understand that for environmentalists from historically underrepresented communities, there are stereotypes and biases that they face on a daily basis, which have emotional and professional impacts. In an attempt to undo some of those stereotypes and build empathy and understanding, the BGC interview questions focus on humanizing the guest and allowing them to express their emotions in a way that is true to their beliefs and personality.

After the release of the podcast, the guest is celebrated the entire week on several social media platforms-Twitter, Instagram, Facebook, and LinkedIn. The celebration entails sharing audio snippets of notable parts of the discussion. Show notes based on the podcast discussion are also published on the podcast website (https://water 
savvysolutions.com/podcast). BGC discussions are always accompanied by respected and reliable sources, provided in the show notes, which supports more education through the podcast. The show notes are presented in an informal, blogstyle format and include an overview of the topics and issues discussed, as well as links to additional resources related to the episode topic.

Ultimately, the goal is for the guests to feel like they have had an opportunity to amplify their voice and also to use their episode as a tool to further share their story and gain recognition within the environmental community and beyond.

\section{Results: topics covered by the BGC podcast}

In order to demonstrate how the principles of intersectionality manifest in environmentalism, provided below are examples of conversations from the BGC podcast. In addition to taking an intersectional approach, the podcast was motivated to support development of holistic ecoliteracy, where guest speakers share interdisciplinary science-based research perspectives to better understand ecosystems while also considering their ethical, cultural, and political dimensions (Hempel 2014). Ultimately, the podcast tries to capture stories that embody a "transdisciplinary form of ecoliteracy that includes experiential learning, knowledge of personal and social responsibility, and understanding of the roles of governance and communication in moving from knowledge to action" (Hempel 2014, p. 45). Based on inductive content analysis (Birch and Weitkamp 2010; Neuman 2006) of the topics covered by invited guests, four main themes emerged from the first podcast season: environmental justice, structural racism and conservation, traditional ecological knowledge, and access to nature and the outdoors.

\section{Environmental justice}

A recurring theme in discussions with podcast guests has been the link between social justice and environmental justice (Table 1). Guests consistently described how they have experienced environmental injustices in their personal and professional lives as it relates to their social identities such as race, gender identity, sexual orientation, disabilities, and so on. For example, a podcast guest Isaias Hernandez (Mulki 2020, episode 11), an environmental educator who runs the Instagram account "QueerBrownVegan," talked about how he grew up in a poor community in southern California that was exposed to air pollution due to proximity to a toxic industrial plant. However, he did not realize his unjust community context until he was much older when he went to school and learned about environmental justice.

Frances Roberts-Gregory (Mulki 2020, Episode 20) is completing her PhD dissertation that focuses on Gulf Coast women of color's climate justice activism and strategies to resist environmental racism while navigating contradictory relationships with energy and petrochemical industries. Roberts-Gregory is an interdisciplinary social scientist who works at the intersection of ecowomanism and climate justice. She talked about the importance of decolonizing her research methods to truly capture the perspectives, mindsets, and experiences of Indigenous women and women of color who are protesting environmental injustices in their neighborhoods (e.g., Roberts-Gregory and Hawthorne 2016).

\section{Structural racism and conservation}

Structural racism has also played a significant role in the lack of racial diversity in most professions, including conservation ecology and the geosciences. As an example, Dr. Jonathan Hall shared that he is the only Black person with a $\mathrm{PhD}$ working on California Condor recovery. Dr. Hall (Mulki 2020, episode 22) is a wildlife ecologist by training with a broad interest in wildlife conservation, human/wildlife interaction, environmental justice, and species movement ecology. In this episode, Dr. Hall went in depth on how structural racism influences his research methodologies and collaboration on recovery of the California Condor.

Structural racism has also historically excluded or limited the role of American Indians in conservation. As a result, as Hall explained during his interview on BGC, collaborations have turned into conflicts between White scientists and Native Tribes regarding who gets to take the lead on conservation work in general, and whether it makes sense, specifically, to reintroduce California Condors to Tribal
Table 1 BGC episodes focused on the theme of environmental justice

\begin{tabular}{lll}
\hline Guest & Podcast episode & Title of podcast episode \\
\hline $\begin{array}{l}\text { Frances Roberts-Gregory } \\
\text { Isaias Hernandez }\end{array}$ & (Mulki 2020) Ep. 20 & On Being a Black Feminist Environmental Ethnographer \\
(Mulki 2020) Ep. 11 & $\begin{array}{l}\text { Making Space for Queer People of Color in the } \\
\text { Environmental Movement }\end{array}$ \\
$\begin{array}{lll}\text { Dr. Ingrid Waldron } & \text { (Mulki 2020) Ep. 10 } & \text { There's Something In the Water } \\
\text { Stacey Isaac Berahzer } & \text { (Mulki 2020) Ep. 3 } & \text { Water Affordability and Equity in America }\end{array}$ \\
\hline
\end{tabular}


lands. Often, European records have taken precedence over Indigenous knowledge and history (Smith 2012).

Another example of how structural racism affects conservation comes from Belinda Chin (Mulki 2020, episode 21), coordinator for the Urban Food Systems Program at Seattle Parks and Recreation. Chin explained that through most of her career, White workplace peers often tokenized and dismissed discriminatory acts toward her. Wanting to understand the prejudice of dominant White environmental organizational culture, she started to educate herself on issues of environmental history and environmental justice. Several BGC more guests have spoken about the issue of structural racism (Table 2).

\section{Traditional ecological knowledge}

Other BGC discussions have focused on the importance of Indigenous knowledge in promoting a viable solution to our environmental challenges (Table 3). Traditional ecological knowledge (TEK) and Indigenous ways of knowing have often been ignored by mainstream environmental movements at the local and global level (Berkes et al. 2000; Kealiikanakaoleohaililani and Giardina 2016). However, there has been growing recognition of the value of TEK and Indigenous and local knowledge (Kimmerer 2015). The topics discussed on BGC under this theme included food sovereignty, cultural fire burning practices, environmental activism, and spiritual healing through connecting with nature.

In the BGC conversations with Indigenous experts, guests shared how the knowledge to manage nature sustainably has been passed down through many generations. The impact of colonialism and capitalism on Indigenous history and culture has been an overarching theme. For example, in the episode with Dr. Mariaelena Huambachano, she talked about how when governments impose processed foods over Indigenous diets, it is often less healthy due to the use of pesticides for mass production. Losing the right to eat, grow, or share food that speaks of your culture and the health of the land is an example of food injustice.

Similarly, Bill Tripp talked about White settler policies that have prevented the Karuk Tribe in Northern California from practicing cultural burns, which have been a major part of the tribal identity for millennia. The BGC discussion also addressed how the dismissal of Indigenous ways of knowing has been the main reason why California fires are increasing in frequency and intensity.

\section{Access to nature and the outdoors}

Disability justice and healing justice are also critical topics that have been covered on BGC. These justice movements have been created by DQTBIPOC activists who are calling for more holistic, thoughtful, and intentional activism (Berne et al. 2018; Jampel 2018). The disability community has struggled with access for decades, and while the 1990 Americans with Disabilities Act has made an impact, design that benefits everyone is still lacking, particularly in accessing outdoor spaces (Houten 2019). Conversations on the BGC podcast with regard to accessibility have pertained mainly to natural spaces such as parks. These included discussions with Vasu Sojitra, a professional adaptive athlete (Mulki 2020, episode 35) and Syren Nagakyrie, the founder of Disabled Hikers (Mulki 2020, episode 23; disabledhikers. com).
Table 2 BGC episodes focused on the theme of structural racism in conservation

\begin{tabular}{lll}
\hline Guest & Episode number & Title of podcast episode \\
\hline Dr. Jonathan Hall & (Mulki 2020) Ep. 22 & Stories From an Ecologist and Aspiring Hunter \\
Belinda Chin & (Mulki 2020) Ep. 21 & Finding a Place to Belong \\
Dr. Justin Dunnavant & (Mulki 2020) Ep. 18 & Unearthing the Lives of Enslaved Africans \\
Jack Shu & (Mulki 2020) Ep. 8 & 29 Years of Insights with California State Parks \\
Raya Salter & (Mulki 2020) Ep. 7 & Making Space for Clean Energy and Climate Justice \\
Fred Tutman & (Mulki 2020) Ep. 4 & Grassroots Action in River Protection \\
\hline
\end{tabular}

Table 3 BGC episodes focused on the theme of traditional ecological knowledge

\begin{tabular}{lll}
\hline Guest and affiliation & Episode number & Title of podcast episode \\
\hline $\begin{array}{l}\text { Rabiah Nur, Black and Indigenous } \\
\begin{array}{l}\text { Dr. Mariaelena Huambachano, Indigenous } \\
\text { Peruvian }\end{array}\end{array}$ & $\begin{array}{l}\text { (Mulki 2020) Ep. 32 } \\
\text { (Mulki 2020) Ep. 25 }\end{array}$ & $\begin{array}{l}\text { Finding Your Spiritual Connection to Mother Earth } \\
\text { Rill Tripp, Karuk }\end{array}$ \\
$\begin{array}{l}\text { Michael T. Charles, Diné } \\
\text { (Mulki 2020) Ep. 24 }\end{array}$ & $\begin{array}{l}\text { Bringing Fire Back to the Karuk Tribe } \\
\text { (Mulki 2020) Ep. } 9\end{array}$ & The Power of Indigenous Youth Environmental Movements
\end{tabular}


Another topic related to accessibility is the lack of representation of people of color in America's parks (Finney 2014). BGC podcast listeners and followers on social media have been especially surprised by the history of erasure as it relates to the creation of US national parks. There has been great interest from followers on BGC's Instagram account on how the "Fathers of Conservation," mainly John Muir, Adam Grant, and Theodore Roosevelt, held racist beliefs toward Black, Indigenous, and People of Color, which resulted in their exclusion from natural spaces during and after the creation of the national park system (Taylor 2016). This topic has created a dialogue on BGC's Instagram account that has included shock, denial, and in some cases anger because it challenges a history that was not part of the mainstream education system and narratives. Ultimately, this is one of the goals of the podcast - to undo and unlearn some of the harmful ways of knowing that have further racialized and minoritized DQTBIPOC. These BGC discussions were with Sarika Tandon, a racial equity and justice consultant (Mulki 2020, episode 30) and Francisco Valenzuela, a former director at the US Forest Service (Mulki 2020, episode 38) (Table 4).

\section{Building a community}

The BGC podcast was launched on February 18, 2020, and since then consistent efforts have been made to build a community around the issues discussed on the podcast. The initial focus of community building has been online. The podcast is on many social media platforms. The intention is that in the next two years there will be possibilities for funding for a virtual conference, which can later be turned into an in-person event. Currently, the BGC podcast does not have sponsors or advertisements. Financial support is needed for operations of the podcast and for creating a hub where environmentalists can connect, collaborate, and create more diverse and supportive movements. Because of the COVID-19 pandemic, lack of funding, and also because it is not easy for DQTBIPOC to make it to inperson events, it is possible that the podcast will remain a virtual community in the near future. Future episodes may include panel discussions with multiple guests speaking on an issue from different perspectives.

The community on social media has been built by continuing the conversation started on the podcast episodes. The successes that the podcast has achieved since it launched include the following (as of May 2021): 20,000 downloads, with an average of 350 downloads per episode; 5,600 followers on Instagram (@ breaking_green_ceilings); 59 followers on our Facebook group and growing (@Breaking Green Ceilings); 135 followers on Twitter and growing (@ sapnamulki). For comparsion, The Podcast Host (2021) said that, "if your new episode gets, within 7 days of its release, more than 26 downloads, you're in the top 50\% of podcasts." The BGC podcast has an average of 350 downloads per episode. It is difficult to make a direct comparison on number of cumulative downloads for other podcasts, since that information is proprietary. Future research could explore this dimension of podcast success.

In addition to building an online presence, the podcast also strives to create meaningful relationships with speakers so that the conversation does not end with the interview. The podcast continues to collaborate with speakers to raise awareness and funds. For example, due to the destructive 2020 California fires (e.g., Slater and Devil Fire 2020), the podcast promoted a fundraiser for the Karuk Tribe in northern California to purchase a fire truck (Karuk Tribe DNR 2020). The podcast has also given to other Black and Indigenous movements such as bailout funds for Black Lives Matter and also for the Lakota Land Defenders.

Additionally, the podcast has connected speakers to each other and we share relevant information with speakers in an effort to continue supporting the work of the guests. Some guests have also been invited for a second interviews in the future to check-in on progress and continue visibility of their work. The hope is that in time we will be able to create an advisory board that would assist in keeping the podcast connected to and in tune with the community issues and able to connect more with DQTBIPOC environmentalists who are making a difference in their communities.

Table 4 BGC episodes that focused on the theme of access to nature and the outdoors

\begin{tabular}{lll}
\hline Guest & Episode & Title of podcast episode \\
\hline Ambika Rajyagor & (Mulki 2020) Ep. 39 & Lending a Voice to Disability Justice and an Outdoors for All \\
Francisco Valenzuela & (Mulki 2020) Ep. 38 & Recreating in Color: Promoting Ethnic Diversity in Public Lands \\
Vasu Sojitra & (Mulki 2020) Ep. 35 & Ninjasticking Through the Woods to Bring Intersectionality to the Outdoors \\
Sarika Tandon & (Mulki 2020) Ep. 30 & Advocating for Racial Equity in the Environmental Movement \\
Syren Nagakyrie & (Mulki 2020) Ep. 23 & Making the Outdoors Accessible to Disabled Hikers \\
Dr. Olivia Aguilar & (Mulki 2020) Ep. 1 & A Journey Through Academia as a Woman of Color
\end{tabular}




\section{Discussion and conclusion}

The BGC podcast has filled a vacant niche, providing a platform to amplify the unheard voices of diverse environmental leaders. As our analysis of environmental podcasts revealed, the podcast network is still predominantly White.

Initially, there was a concern about the podcast running out of guests to interview. However, this has definitely not been the case. Hosting the podcast has revealed many things. Clearly, there is a great need for this type of content, to educate the mainstream environmental movement about the many existing DQTBIPOC leaders. As organizations seek to diversify their members and boards, and educate themselves about equity in the environmental field, the BGC podcast can serve as a resource. It can also continue to break stereotypes and implicit bias within the environmental field.

Larger media networks should also make efforts to invite and feature DQTBIPOC guests. The excuse that "we cannot find a speaker of color" is no longer acceptable-there are whole organizations providing suggestions of diverse environmental speakers (DELSB 2020).

Additionally, the podcast contributes to building ecoliteracy and just sustainability, and supporting a movement where listeners can imagine their role in creating positive change. The goal is not only to educate listeners about the science of ecological systems, but also to show the roles that human actions, perceptions and cultures play on the overall health of the natural environment, including related social and economic issues.

Future podcasts will explore more grassroot movements and efforts, including issues of food sovereignty and queer ecology. In the coming year, episodes may cover park rangers globally and challenges they face. The podcast will also explore how to include traditional ecological knowledge approaches within global environmental policy, governance, and conservation efforts.

The BGC podcast has filled a gap; however, there is still more work that needs to be done. We need holistic, collaborative solutions to the complex environmental problems we are facing. We will keep assessing the relevance of the podcast, and adapt to future topics and challenges.

Ultimately, the podcast seeks to create solidarity in the environmental movement by increasing understanding and empathy for historically underrepresented communities and to see underrepresented environmentalists as leaders and problem solvers. The podcast is only in the beginning stages of its journey and hopefully increased future collaboration will take it beyond the airwaves.

Supplementary Information The online version contains supplementary material available at https://doi.org/10.1007/s13412-021-00723-z.
Acknowledgements We would like to thank our parents and our families for the support they have provided us throughout this process of building the podcast. We also thank Julian Virag, the podcast producer, and Kasidy Martin, the social media content coordinator who have been critical to the day-to-day operations and outreach. We express our gratitude to peer support groups-including Women of Color Podcasters and She Podcasts-for being a source of information, comfort, and inspiration.

\section{Declarations}

Conflict of interest The authors declare no competing interests.

\section{References}

Agyeman J (2005) Sustainable communities and the challenge of environmental justice. New York University Press, New York

Alexander M (2010) The New Jim Crow: mass incarceration in the age of colorblindness. The New Press, New York

Barrios-O'Neill D (2018) Wild listening: ecology of a science podcast. In: Llinares D, Fox N, Berry R (eds) Podcasting: New Aural Cultures and Digital Media. Palgrave Macmillan, London, pp $147-172$

Berkes F, Colding J, Folke C (2000) Rediscovery of traditional ecological knowledge as adaptive management. Ecol Appl 10(5):1251-1262

Berne P, Morales AL, Langstaff D (2018) Ten principles of disability justice. Women's Stud Q 46(1 \& 2):227-230. https://doi.org/10. 1353/wsq.2018.0003

Birch H, Weitkamp E (2010) Podologues: conversations created by science podcasts. New Media Soc 12(6):889-909

Bottomley AJ (2015) Podcasting: a decade in the life of a "new" audio medium: introduction. J Radio Audio Media 22(2):164-169

Brundtland Commission (1987) Report of the World Commission on Environment and Development: our common future. Oxford University Press, Oxford

Crenshaw K (2015) Why intersectionality can't wait. The Washington Post. Sept. 24. https://www.washingtonpost.com/news/in-theory/ wp/2015/09/24/why-intersectionality-cant-wait/. Accessed 1 Nov 2020

Crenshaw K (1989) Demarginalizing the intersection of race and sex: a Black feminist critique of antidiscrimination doctrine, feminist theory and antiracist politics. Univ Chic Leg Forum 1989(1), Article 8. http://chicagounbound.uchicago.edu/uclf/vol1989/iss1/8

Diverse Environmental Leaders Speakers Bureau (DELSB). (2020) Our Speakers. https://www.delnsb.com/. Accessed 9 November 2020

Finney C (2014) Black faces, White spaces: reimagining the relationship of African Americans to the great outdoors. The University of North Carolina Press, Durham

Hammersley B (2004) "Audible revolution". The Guardian. Archived from the original on 2013-09-22. https://www.theguardian.com/ media/2004/feb/12/broadcasting.digitalmedia. Accessed 1 Nov 2020

Hempel M (2011) The sustainability test. Sustainability 4(2):47-48. https://doi.org/10.1089/SUS.2011.9714

Hempel M (2014) Ecoliteracy: knowledge is not enough. p. 41-52 in Worldwatch Institute. State of the World: Governing for Sustainability. Washington, DC: Island Press

Houten AV (2019) "A new adventure guide for people with disabilities." Outside. https://www.outsideonline.com/2403046/disabledhikers-syren-nagakyrie. Accessed 5 Nov 2020 
Jampel C (2018) Intersections of disability justice, racial justice and environmental justice. Environ Sociol 4(1):122-135. https://doi. org/10.1080/23251042.2018.1424497

Karuk Tribe Department of Natural Resources (2020) Endowed capacity - fire engine fundraiser. https://connect.clickandpledge.com/ Organization/karuk/campaign/Fire_Truck. Accessed 9 Nov 2020

Kealiikanakaoleohaililani K, Giardina CP (2016) Embracing the sacred: an indigeous framework for tomorrow's sustainability science. Sustain Sci 11:57-67. https://doi.org/10.1007/ s11625-015-0343-3

Kimmerer RW (2015) Braiding sweetgrass: indigenous wisdom, scientific knowledge and the teachings of plants. Minneapolis, MN: Milkweed Editions

Listen Notes (2020) "Podcast Stats: how many podcasts are there?" https://www.listennotes.com/podcast-stats/. Accessed 25 Oct 2020

Markman KM, Sawyer CE (2014) Why pod? Further explorations of the motivations for independent podcasting. J Radio Audio Media 21(1):20-35

Mulki S (Host) (2020, episode 1). A journey through academia as a woman of color. [Audio podcast episode]. In Breaking Green Ceilings. Water Savvy Solutions. https://watersavvysolutions.com/ navigating-academia/. Accessed 30 Sept 2021

Mulki S (Host) (2020, episode 3). Water affordability and equity in America. [Audio podcast episode]. In Breaking Green Ceilings. Water Savvy Solutions. https://watersavvysolutions.com/wateraffordability-and-equity-in-america/. Accessed 30 Sept 2021

Mulki S (Host) (2020, episode 4). Grassroots action in river protection. [Audio podcast episode]. In Breaking Green Ceilings. Water Savvy Solutions. https://watersavvysolutions.com/grassrootsaction/. Accessed 30 Sept 2021

Mulki S (Host) (2020, episode 8). 29 years of insights with California State Parks. [Audio podcast episode]. In Breaking Green Ceilings. Water Savvy Solutions.https://watersavvysolutions.com/29-yearsof-insights-with-california-state-parks/. Accessed 30 Sept 2021

Mulki S (Host) (2020, episode 9). The power of indigenous youth environmental movements. [Audio podcast episode]. In Breaking Green Ceilings. Water Savvy Solutions. https://watersavvysolut ions.com/the-power-of-indigenous-youth-environmental-movem ents/. Accessed 30 Sept 2021

Mulki S (Host) (2020, episode 10). There's something in the water. [Audio podcast episode]. In Breaking Green Ceilings. Water Savvy Solutions. https://watersavvysolutions.com/theres-somet hing-in-the-water/. Accessed 30 Sept 2021

Mulki S (Host) (2020, episode 11). Making space for queer people of color in the environmental movement. [Audio podcast episode]. In Breaking Green Ceilings. Water Savvy Solutions. https://water savvysolutions.com/making-space-for-queer-people-of-color/. Accessed 30 Sept 2021

Mulki S (Host) (2020, episode 18). Unearthing the lives of enslaved Africans. [Audio podcast episode]. In Breaking Green Ceilings. Water Savvy Solutions. https://watersavvysolutions.com/unear thing-the-lives-of-enslaved-africans/. Accessed 30 Sept 2021

Mulki S (Host) (2020, episode 20). On being a Black feminist environmental ethnographer. [Audio podcast episode]. In Breaking Green Ceilings. Water Savvy Solutions. https://watersavvysolut ions.com/on-being/. Accessed 30 Sept 2021

Mulki S (Host) (2020, episode 21). Finding a place to belong. [Audio podcast episode]. In Breaking Green Ceilings. Water Savvy Solutions. https://watersavvysolutions.com/a-place-to-belong/. Accessed 30 Sept 2021

Mulki S (Host) (2020, episode 22). Stories from an ecologist and aspiring hunter. [Audio podcast episode]. In Breaking Green Ceilings. Water Savvy Solutions. https://watersavvysolutions.com/storiesfrom-an-ecologist-and-aspiring-hunter/. Accessed 30 Sept 2021

Mulki S (Host) (2020, episode 23). Making the outdoors accessible to disabled hikers. [Audio podcast episode]. In Breaking Green
Ceilings. Water Savvy Solutions. https://watersavvysolutions. com/disabled-hikers/. Accessed 30 Sept 2021

Mulki S (Host) (2020, episode 24). Bringing fire back to the Karuk tribe. [Audio podcast episode]. In Breaking Green Ceilings. Water Savvy Solutions. https://watersavvysolutions.com/bringing-fireback/. Accessed 30 Sept 2021

Mulki S (Host) (2020, episode 25). Reclaiming indigenous rights to food sovereignty. [Audio podcast episode]. In Breaking Green Ceilings. Water Savvy Solutions. https://watersavvysolutions. com/indigenous-rights/. Accessed 30 Sept 2021

Mulki S (Host) (2020, episode 30). Advocating for racial equity in the environmental movement. [Audio podcast episode]. In Breaking Green Ceilings. Water Savvy Solutions. https://watersavvysolut ions.com/racial-equity. Accessed 30 Sept 2021

Mulki S (Host) (2020, episode 32). Finding your spiritual connection to mother earth. [Audio podcast episode]. In Breaking Green Ceilings. Water Savvy Solutions. https://watersavvysolutions.com/ spiritual/. Accessed 30 Sept 2021

Mulki S (Host) (2020, episode 35). Ninjasticking through the woods to bring intersectionality to the outdoors. [Audio podcast episode]. In Breaking Green Ceilings. Water Savvy Solutions. https://water savvysolutions.com/ninjasticking/. Accessed 30 Sept 2021

Mulki S (Host) (2020, episode 38). Recreating in color: promoting ethnic diversity in public lands. [Audio podcast episode]. In Breaking Green Ceilings. Water Savvy Solutions. https://watersavvysolut ions.com/recreating-in-color/. Accessed 30 Sept 2021

Mulki S (Host). (2020, episode 39). Lending a voice to disability justice and an outdoors for all. [Audio podcast episode]. In Breaking Green Ceilings. Water Savvy Solutions. https://watersavvysolut ions.com/lending-a-voice/. Accessed 30 Sept 2021

Mulki S (Host) (2020, episode 40). Bringing back buffalo to native lands and peoples. [Audio podcast episode]. In Breaking Green Ceilings. Water Savvy Solutions. https://watersavvysolutions. com/buffalo. Accessed 30 Sept 2021

Neuman WL (2006) Social research methods: quantitative and qualitative approaches. Allyn and Bacon, Boston

Pellow DN (2018) What is critical environmental justice? Polity Press, Medford

Piepzna-Samarasinha LL (2018) Care work: dreaming disability justice. Arsenal Pulp Press, Vancouver

The Podcast Host (2021) Average podcast downloads: what's a good gauge for my podcast? Accessed 3 May 2021 from https://www. thepodcasthost.com/planning/whats-a-good-number-of-downl oads-for-a-podcast/

Roberts-Gregory F, Hawthorne TL (2016) Transforming green walls into green places: Black middle class boundary work, multidirectional miscommunication and greenspace accessibility in southwest Atlanta. Geoforum 77:17-27. https://doi.org/10.1016/j.geofo rum.2016.09.016

Ruoff M (2018) "How much does a podcast cost?" https://live365. com/blog/how-much-does-a-podcast-cost/. Accessed 5 Nov 2020

Smith LT (2012) Decolonizing methodologies: research and indigenous people. Zed Books, New York

Taylor DE (2014) The state of diversity in environmental organizations: mainstream NGOs, foundations, and government agencies. https:// www.diversegreen.org/wp-content/uploads/2015/10/FullReport_ Green2.0_FINAL.pdf

Taylor DE (2016) The rise of the American conservation movement: power, privilege, and environmental protection. Duke University Press, Durham

Publisher's note Springer Nature remains neutral with regard to jurisdictional claims in published maps and institutional affiliations. 